\title{
Index System of Agriculture Industrial Cluster Network Innovation Capability Evaluation
}

\author{
Wang Yumei \\ University of International Business and Economics \\ Beijing, China \\ Ocean University of China \\ Qingdao, China \\ E-mail: Sixu1016@163.com
}

\begin{abstract}
On the basis of analyzing the elements of the network innovation ability of agricultural industry cluster, the evaluation system of network innovation capability of agricultural industry cluster is constructed, based on resources, network and capability. It selects the 27 original indicators of measuring the network innovation ability of the cluster, and uses the factor analysis model to carry out the applied research.
\end{abstract}

Keywords-Agriculture; Industrial cluster; Network innovation; Evaluation system;

\section{INTRODUCTION}

Industrial cluster is an important part of development of the world economy, it is the driving force to promote regional economic and industrial development. Since 1990s, the agricultural industry cluster has developed rapidly, and some characteristic agricultural industrial clusters have become the pillar industry in some countries and regions [1-3]. It takes some agricultural products as the core, including agricultural producers, processors, distributors and scientific research institutions, to achieve a competitive advantage.

Many developed countries introduced the relevant policies to ensure the development of agricultural industry cluster, such as the EU's financial support policies, the United States agricultural technology promotion system and so on[4-5]. Network innovation ability is an important aspect for the development of agricultural industry clusters. Domestic and foreign theory and practice experience shows that, in the early stage of development, the agricultural industry cluster obtain competitive status mainly depends on the location and 1 resource endowment advantage [6]. However, the market competition is becoming increasingly fierce, and the continuous advance of economic globalization, which makes the innovation ability become the key factor of industrial cluster competitiveness. In order to maintain sustainable competitive advantage, agricultural industry cluster must focus on the cooperative development of the main

Fund project: Qingdao social science planning project (QDSKL1501070); Provincial statistical research key topics (KT15055); Humanities and social sciences project of Qingdao University of Science and Technology (14XB18); Shandong province key topics of arts and sciences (1506579); Qingdao soft science project (15-9-2-1-(2)-zhc); National statistical research project (2015LY09); University research development program of Shandong province (J13WG25); National Natural Science Foundation of China(71540017).

\author{
Wang Wei, Wang Linghui \\ Qingdao University of Science and Technology \\ Qingdao, China \\ E-mail: 45941991@qq.com; 1393238592@qq.com
}

body, and create the network innovation platform of industry cluster. So it can enhance the adaptability of the environment in the complex and changeable environment, improve the competitive advantage of the cluster through the interaction and the resource sharing [7].

\section{ANALYSIS ON THE ELEMENTS OF NETWORK INNOVATION ABILITY OF AGRICULTURAL INDUSTRY CLUSTER}

The key to the innovation of agricultural industrial cluster is to integrate resources in the flow of resources and accelerate the resource allocation efficiency. However, only the resources and the relationship is not enough, but also need to absorb the resources and convert into their own competitiveness. Therefore, this paper constructs an analysis framework of network innovation capability of agricultural industry cluster, which is composed of the internal resources, network resources and absorptive capacity of the cluster. As

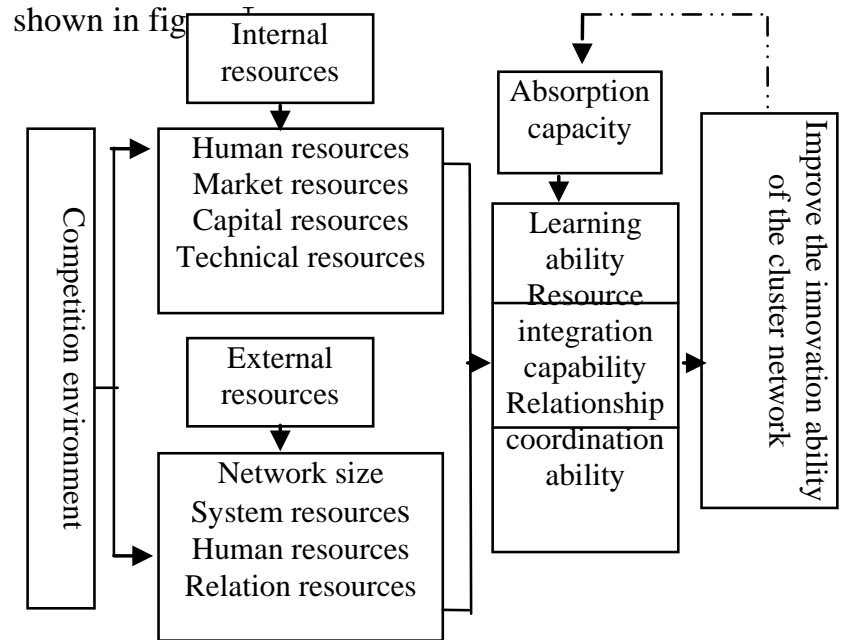

Fig. I: Analysis frame of network innovation ability of agricultural industry cluster

\section{CONSTRUCTION OF EVALUATING INDEX SYSTEM OF AGRICULTURAL INDUSTRY CLUSTER NETWORK INNOVATION ABILITY}

Based on the analysis of the innovation capability of the "resources - Network - capacity", this paper establishes the evaluation index system of agricultural industrial cluster network innovation ability. As shown in Table I. 
TABLE I. CONSTITUTION OF EVALUATION INDEX SYSTEM OF AGRICULTURAL INDUSTRY CLUSTER NETWORK INNOVATION ABILITY

\begin{tabular}{|c|c|c|}
\hline Target layer & Standard layer & Index layer \\
\hline \multirow{8}{*}{$\begin{array}{c}\text { Internal } \\
\text { resources (A) }\end{array}$} & \multirow{2}{*}{$\begin{array}{l}\text { Human resources } \\
\text { (A1) }\end{array}$} & The proportion of R \& D staff of enterprise workers (A11) \\
\hline & & The extent of employee participation in enterprise management (A12) \\
\hline & \multirow{2}{*}{$\begin{array}{l}\text { Capital resources } \\
\text { (A2) }\end{array}$} & R \& D expenditure to total revenue ratio（A21） \\
\hline & & Training funding to total income ratio (A22) \\
\hline & \multirow{2}{*}{$\begin{array}{l}\text { Technical resources } \\
\text { (A3) }\end{array}$} & Popularity of technical regulations (A31) \\
\hline & & Technological transformation strength (A32) \\
\hline & \multirow{2}{*}{$\begin{array}{c}\text { Market resources } \\
\text { (A4) }\end{array}$} & Brand connotation renewal speed (A41) \\
\hline & & Market channel development (A42) \\
\hline \multirow{9}{*}{$\begin{array}{l}\text { Internet } \\
\text { resources } \\
\text { (B) }\end{array}$} & \multirow{4}{*}{$\begin{array}{l}\text { Network size } \\
\text { (B1) }\end{array}$} & Production environment (B11) \\
\hline & & construction scale (B12) \\
\hline & & Infrastructure (B13) \\
\hline & & Number of R \& D Center（B14） \\
\hline & \multirow{3}{*}{$\begin{array}{l}\text { System Construction } \\
\text { (B2) }\end{array}$} & Regional industry and tax policy (B21) \\
\hline & & The perfection of the mechanism of venture capital（B22） \\
\hline & & Specification for agricultural market cluster degree（B23） \\
\hline & \multirow{2}{*}{$\begin{array}{l}\text { Network subject } \\
\text { interaction (B4) }\end{array}$} & Interaction frequency between the network main body (B41) \\
\hline & & The rationality of cluster value chain (A42) \\
\hline \multirow{10}{*}{$\begin{array}{l}\text { Absorption } \\
\text { capacity } \\
\text { (C) }\end{array}$} & \multirow{2}{*}{$\begin{array}{l}\text { Profitability } \\
\quad \text { (C1) }\end{array}$} & New product output value (C11) \\
\hline & & New product exports to create foreign exchange (C12) \\
\hline & \multirow{2}{*}{$\begin{array}{l}\text { Cultural innovation } \\
\text { ability (C2) }\end{array}$} & Innovative atmosphere of cluster network (C21) \\
\hline & & Cluster network construction investment level of innovation culture (C22) \\
\hline & \multirow{2}{*}{$\begin{array}{l}\text { Brand innovation } \\
\text { ability (C3) }\end{array}$} & Product certification ( C31) \\
\hline & & Brand influence (C32) \\
\hline & \multirow{2}{*}{$\begin{array}{c}\text { Technological } \\
\text { innovation ability } \\
\text { (C4) }\end{array}$} & The effectiveness of new product development (C41) \\
\hline & & New products and new technology number (C42) \\
\hline & \multirow{2}{*}{$\begin{array}{c}\text { Cluster network } \\
\text { architecture (C5) }\end{array}$} & Network stability（C51） \\
\hline & & Degree of resource integration between network entities (C52) \\
\hline
\end{tabular}

IV. APPLICATION OF NETWORK INNOVATION EVALUATION INDEX SYSTEM OF AGRICULTURAL INDUSTRY CLUSTER, TAKE QINGDAO CITY AS AN EXAMPLE

\section{A. Research objects and data collection}

In this paper, the agricultural industry cluster of Qingdao city as the research object, combined with the development of the agricultural industry cluster in Qingdao, made the corresponding questionnaire based on the index. And for the Qingdao milling industry, poultry processing, peanuts, seafood, vegetable processing five industry clusters and Agriculture
Bureau issued a questionnaire. A total of 125 copies distributed, the actual recovery of 112 valid questionnaires, of which milling industry 18 parts, 17 parts of poultry processing, 20 parts of peanut, seafood, 18 parts, 17 parts vegetable processing, 21 parts Agriculture Bureau. Questionnaire response rate was $89.6 \%$.

\section{B. Factor analysis process}

Factor analysis model: $\mathrm{X}=\mathrm{AF}+\Sigma$. $\mathrm{X}$ represents the original variable can be observed; $F$ represents a small number of unobservable common factor; $\Sigma$ represents a special factor. 
That is, $\mathrm{X}_{\mathrm{i}}=\mathrm{a}_{\mathrm{i} 1} \mathrm{~F}_{1}+\mathrm{a}_{\mathrm{i} 2} \mathrm{~F}_{2}+\ldots+\mathrm{a}_{\mathrm{im}} \mathrm{F}_{\mathrm{m}}+\Sigma$, where, $\mathrm{a}_{\mathrm{ij}}$ is the $\mathrm{i}$-th variable in the $\mathrm{j}$-th load factor, which is called the factor load.

In this paper, the selection of the original index is analyzed by using SPSS21.0 software. The results show that the KMO value is $0.626>0.5$, and the Sig value is $0.00<0.05$. This shows that there is a strong correlation between indicators and it is suitable for factor analysis. The characteristic root and variance contribution rate of the agricultural industry cluster network innovation factors in Qingdao are obtained, according to the correlation coefficient matrix. As shown in Table II.

TABLE II. CHARACTERISTIC VALUE, CONTRIBUTION RATE

\begin{tabular}{|c|c|c|c|}
\hline \multirow{2}{*}{ Factor } & \multicolumn{3}{|c|}{ Non-rotated square and loading } \\
\cline { 2 - 4 } & Eigenvalue & $\begin{array}{c}\text { Variance } \\
\text { contribution } \\
\text { rate \% }\end{array}$ & $\begin{array}{c}\text { Cumulative variance } \\
\text { contribution } \\
\text { rate \% }\end{array}$ \\
\hline 1 & 6.291 & 23.299 & 23.299 \\
\hline 2 & 4.923 & 18.235 & 41.534 \\
\hline 3 & 3.428 & 12.697 & 54.231 \\
\hline 4 & 2.662 & 9.859 & 64.090 \\
\hline 5 & 2.355 & 8.721 & 72.811 \\
\hline 6 & 2.020 & 7.480 & 80.291 \\
\hline \multirow{2}{*}{ Factor } & & Rotation square and loading \\
\cline { 2 - 4 } & Eigenvalue & $\begin{array}{c}\text { Variance } \\
\text { contribution } \\
\text { rate \% }\end{array}$ & $\begin{array}{c}\text { Cumulative variance } \\
\text { contribution } \\
\text { rate \% }\end{array}$ \\
\hline 1 & 4.885 & 18.092 & 18.092 \\
\hline 2 & 4.792 & 17.746 & 35.839 \\
\hline 3 & 3.939 & 14.590 & 50.429 \\
\hline 4 & 2.899 & 10.735 & 61.164 \\
\hline 5 & 2.867 & 10.617 & 71.781 \\
\hline 6 & 2.298 & 8.510 & 80.291 \\
\hline
\end{tabular}

By Table II, the former six factors of the correlation matrix of the variables explain $80.291 \%$ of the variance of the standard. It shows that the former six factors reflect the majority of the information provided by the original data. In order to strengthen the capacity of the common factors to explain the actual problem, extracted six common factors create the original factor loading matrix. And maximize the use of variance orthogonal rotation method for rotating the load factor matrix to obtain the rotated loading matrix.

The load value of the common factor F1 in the B11, B13, B12, B14 and B21 is large. It is named as the basic environment in the content analysis. Similarly, F2 is named as the research and development capital in the content analysis, F3 is named as profitability, F4 is named as cluster auxiliary support systems, F5 is named as innovation culture construction of public factor cluster, F6 is named as cluster brand construction.

As shown in Table III. Factor scores can be calculated according to the matrix and the variable observed values. The formula is:

$$
\begin{aligned}
& F 1=0.002 X_{1}-0.018 X_{2}+0.011 X_{3}+\ldots-0.060 X_{26}-0.071 X_{27} \\
& F 2=0.204 X_{1}-0.001 X_{2}+0.20 X_{3}+\ldots+0.043 X_{26}+0.050 X_{27} \\
& F 3=-0.004 X_{1}+0.004 X_{2}-0.013 X_{3}+\ldots+0.008 X_{26}+0.009 X_{27} \\
& F 4=-0.013 X_{1}-0.200 X_{2}-0.001 X_{3}+\ldots+0.254 X_{26}+0.253 X_{27} \\
& F 5=0.000 X_{1}+0.336 X_{2}+0.000 X_{3}+\ldots+0.051 X_{26}+0.060 X_{27} \\
& F 6=-0.023 X_{1}+0.013 X_{2}-0.047 X_{3}+\ldots-0.027 X_{26}-0.032 X_{27}
\end{aligned}
$$

\begin{tabular}{|c|c|c|c|c|c|c|}
\hline & \multicolumn{6}{|c|}{ Element } \\
\hline & 1 & 2 & 3 & 4 & 5 & 6 \\
\hline Proportion of R \& D staff of enterprise workers（A11） & .002 & .204 & -.004 & - & .000 & -.023 \\
\hline Extent of employee participation in enterprise management (A12) & -.018 & -.001 & .004 & - & .336 & .013 \\
\hline R \& D expenditure to total revenue ratio (A21) & .011 & .200 & -.013 & - & .000 & -.047 \\
\hline Training funding to total income ratio (A22) & -.010 & .203 & .001 & .001 & -.004 & -.016 \\
\hline Popularity of technical regulations (A31) & -.002 & 208 & -.009 & .005 & -.010 & -.021 \\
\hline Technological transformation strength (A32) & -.008 & .205 & .003 & .018 & -.007 & -.023 \\
\hline Brand connotation renewal speed (A41) & -.047 & -.015 & -.014 & .094 & .020 & .348 \\
\hline Market channel development (A42) & -.037 & -.017 & -.013 & .084 & .006 & .348 \\
\hline Production environment（B11） & .211 & .001 & -.032 & - & -.009 & -.028 \\
\hline Construction scale (B12) & .215 & -.003 & -.028 & - & -.024 & -.046 \\
\hline Infrastructure（B13） & .202 & .005 & -.032 & - & .000 & .003 \\
\hline Number of R \& D center（B14） & .207 & .013 & -.028 & - & .000 & -.033 \\
\hline Regional industry and tax policy (B21) & .212 & -.003 & -.020 & - & -.013 & -.023 \\
\hline Perfection of the mechanism of venture capital（B22） & .060 & -.055 & -.044 & .189 & -.062 & .127 \\
\hline Specification for agricultural market cluster degree (B23) & .041 & -.054 & -.032 & .207 & -.058 & .138 \\
\hline Interaction frequency between the network main body (B41) & -.029 & -.005 & .014 & .227 & -.032 & -.007 \\
\hline Rationality of cluster value chain (A42) & -.012 & -.014 & .026 & .201 & -.061 & -.016 \\
\hline New product output value (C11) & -.034 & -.004 & .260 & .013 & -.008 & -.008 \\
\hline
\end{tabular}

TABLE III. FACTOR SCORE MATRIX 


\begin{tabular}{|c|c|c|c|c|c|c|}
\hline New product exports to create foreign exchange (C12) & -.040 & -.005 & .258 & .009 & .007 & .003 \\
\hline Innovative atmosphere of cluster network (C21) & -.011 & -.005 & -.001 & - & .342 & .012 \\
\hline Cluster network construction investment level of innovation culture (C22) & -.013 & -.013 & -.004 & - & .336 & .023 \\
\hline Product certification (C31) & .020 & -.034 & .017 & - & .022 & .302 \\
\hline Brand influence (C32) & .017 & -.036 & .021 & - & .012 & .296 \\
\hline Effectiveness of new product development (C41) & -.034 & -.005 & .257 & - & .002 & .003 \\
\hline New products and new technology number (C42) & -.037 & -.002 & .258 & .022 & -.001 & -.008 \\
\hline Network stability (C51) & -.060 & .043 & .008 & .254 & .051 & -.027 \\
\hline Degree of resource integration between network entities (C52) & -.071 & .050 & .009 & .253 & .060 & -.032 \\
\hline
\end{tabular}

The $b_{j}$ is the main factor of the variance contribution rate, then $\mathrm{b}_{\mathrm{j}}=\lambda_{\mathrm{j}} / \mathrm{P} . \mathrm{P}=\lambda_{1}+\lambda_{2}+\lambda_{3}+\ldots+\lambda_{\mathrm{m}}$. In this paper, the main factor is the number 6 , that $\mathrm{m}=6$, then $\mathrm{F}$ $=0.225 \mathrm{~F} 1+0.221 \mathrm{~F} 2+0.182 \mathrm{~F} 3+0.134 \mathrm{~F} 4+0.132 \mathrm{~F} 5+0.106 \mathrm{~F} 6$.

From this, the single factor score and comprehensive factor scores of network innovation of agricultural industry cluster can be calculated respectively. As shown in Table IV.

TABLE IV. QINGDAO AGRICULTURAL INDUSTRY CLUSTER NETWORK INNOVATION EVALUATION INDEX OF INPUT INDEX SCORE SUMMARY TABLE

\begin{tabular}{|c|c|c|c|c|c|c|}
\hline Specific clusters & F1 & S & F2 & S & F3 & S \\
\hline Milling industry & 1.768 & 3 & 2.341 & 5 & 2.359 & 3 \\
\hline Poultry processing & 1.549 & 1 & 2.289 & 4 & 2.389 & 5 \\
\hline Peanuts & 1.878 & 5 & 1.567 & 1 & 1.853 & 1 \\
\hline Seafood & 1.578 & 2 & 1.929 & 2 & 2.147 & 2 \\
\hline Vegetable processing & 1.786 & 4 & 2.093 & 3 & 2.386 & 4 \\
\hline Qingdao agricultural & 1.712 & & 2.044 & & 2.227 & \\
\hline
\end{tabular}

Detailed analysis of six common factors of agricultural industry cluster innovation network evaluation in Qingdao. The basic environmental F1 is better in the analysis of the network innovation level. It shows that the geographical environment of Qingdao city and the construction of the local infrastructure are suitable for the development of the cluster. And the government's industrial policy and tax policy are also very good to stimulate the development of local clusters. Cluster Innovation culture construction F5 and R \& D capital investment F2 are also at a high level. However, cluster peripheral main support F4 is not enough. It indicates that the communication between the main bodies of the cluster is less. And it has lower resource integration level. Brand building F6 is still to be strengthened.

Detailed analysis of six common factors in different clusters, on the basis of $F_{1}$, five industrial clusters are in good level. In particular, seafood and poultry processing have absolute advantage in the production environment and infrastructure. In $\mathrm{F}_{2}$, milling industry and livestock processing industry cluster development capital investment is low, which means that it needs to further increase investment in $\mathrm{R} \& \mathrm{D}$ funding, $\mathrm{R} \& \mathrm{D}$ personnel and training funds etc. In $\mathrm{F}_{3}$, the peanut industry cluster has a strong profitability, because longer industry chain has produced a lot of by-products. In $\mathrm{F}_{4}$, almost all of the clusters are in a poor state, especially the vegetable processing industry cluster. This is because most companies in the cluster lack of interaction with the surrounding body, making the integration of resources is not high. In $\mathrm{F}_{5}$, the level of the five industrial clusters is not very high, which reflects the lack of agricultural industry cluster in

the network innovation atmosphere and innovation cohesion in a certain extent. In $\mathrm{F}_{6}$, in addition to the peanut and seafood, other industrial clusters of brand culture construction should be strengthened.

\section{CONCLUSION}

Agricultural industrial cluster network innovation is a systematic engineering. It needs to analyze the actual situation of the regional industrial clusters, and also need to cooperate with the enterprises, the government and support organizations.

Firstly, enterprises should strengthen the independent innovation ability. Secondly, the government should improve the regional innovation platform, build a good infrastructure and efficient information network, and promote regional industrial chain to high-end expansion through planning or policy guidance. Thirdly, focus on establishing and improving the intermediary organizations which are closely related to the development of agricultural industry clusters according to the actual situation of regional agriculture. In order to further optimize the agricultural industry cluster innovation network, it should establish financing and venture capital system, improve the multi-channel financing system, give full play to the role of industry associations, Academy of Agricultural Sciences and Information Center and other institutions. Finally, in order to rapidly achieve resource optimization allocation and the complementary advantages of the main body, improve the efficiency and effectiveness of technological innovation, research integration of agriculture industrial cluster cooperation system should be built.

\section{Reference}

[1] Bothwell R. Successful industrial innovation: critical factors for the1990s.R\&D 1992(03).

[2] Steinle C, Schiele H. When do industries cluster? A proposal on how to assess an industry's propensity to concentrate at a single region or nation [J].Research Policy, 2002, 31(6):849-858.

[3] Elicia M. Maine, Daniel M. Shapiro, Aidan R. Vining. The role of clustering in the growth of new technology-based firms [J]. Small Business Economics, February 2010, Volume 34, Issue 2, pp 127-146.

[4] Mark J. Ahn, Anne S. York. Resource-based and institution-based approaches to biotechnology industry development in Malaysia [J].Asia Pacific Journal of Management .June 2011, Volume 28, Issue 2, pp 257-275.

[5] Piotr Pachura PhD. Regional Cohesion. Clustering and Networking in Regional Policy [J]. Contributions to Economics, 2010:7-31.

[6] Wang Jici. Innovation in space: enterprise clusters and regional development [J]. Peking University, 2001.

[7] Li Xibao. Empirical research on regional innovation environment of innovation activities efficiency [J]. Quantitative and technical economics research, 2007. 